\title{
The role of social networks in the inclusion of small-scale producers in agri- food developing clusters ${ }^{\text {th }}$
}

\author{
Matias Ramirez $^{\mathrm{a}, *}$, Paloma Bernal $^{\mathrm{a}}$, Ian Clarke ${ }^{\mathrm{b}}$, Ivan Hernandez ${ }^{\mathrm{c}}$

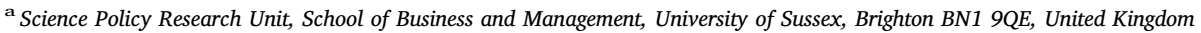 \\ ${ }^{\mathrm{b}}$ Department of Systems Management and Strategy, University of Greenwich, United Kingdom \\ ${ }^{\mathrm{c}}$ University of Ibague, Colombia
}

\begin{abstract}
A B S T R A C T
This paper discusses how network theory and social capital can help explain different patterns of inclusion of small and medium sized producers in agri-food clusters. We make the argument that despite the centralized nature of practices, the manner in which inclusion takes place can vary significantly depending on structural features of local networks and governance factors, especially social capital and the role of lead organisations. Social network analysis allows us to investigate how different patterns of bonding, bridging and centrality of key actors in agricultural clusters can influence diffusion of knowledge. We frame this discussion through a typology that allows us to identify diverse scenarios of inclusion of small producers. This is then used to guide an empirical analysis of two agri-food clusters of small producers in Peru (mango) and Colombia (palm oil). Judicious use of mixed methods and the typology can prove useful to explain diverse patterns of inclusion which have important implications for small-scale agricultural producers.
\end{abstract}

\section{Introduction}

A significant body of policy thinking views the growth and spread of agribusiness and specifically agri-food activity in economically developing countries as a positive step for small-scale agricultural producers (Kumar et al., 2010; UNDP, 2010; Vorley et al., 2008¹). The opportunities to open new markets can act as a spur for investment in infrastructure in rural areas and the provision of agricultural extension services can enhance productivity and knowledge transfer capabilities for small-scale farmers. However, other voices raise concerns and associate incorporation of small-scale producers in commodity export activity with over-dependence of vulnerable farmers on unstable markets and over-reliance on large buyer firms (Cáceres, 2015; Markelova et al., 2009 ${ }^{2}$ ). Hence, although growth of agri-food activities is considered an important policy tool to allow hitherto marginalised farming communities to gain a foothold in expanding markets (Gomes, 2007; McCormick, 1999), the dynamics of inclusion may be quite different for small-scale producers. The question that we address in this paper is how different local arrangements around construction of local networks and network governance can lead to diverse forms of inclusion that have contrasting outcomes for small-scale producers in terms of access to knowledge and new practices.

By the term inclusion we refer to the insertion of small-scale producers in local networks of knowledge transfer that exist to supply agribusiness markets. We are therefore particularly interested in the structure and governance of these networks at the cluster level where small-scale producers are agglomerated. Structures of social networks provide insights into the connectedness of actors and their social capital and they can also show the diversity of knowledge available to actors and the resources actors have at their disposal (Cagnin et al., 2012; Carpenter et al., 2012). Governance of networks on the other hand can explain how new technologies and practices are introduced and the agency of specific actors (Mansuri and Rao, 2013). Our approach therefore addresses a concern that existing studies of diffusion of technology in agri-food contexts, that often focus on relationships within chains of production, can often leave out local dynamics.

\footnotetext{
All surveys and original data are available on mr230@sussex.ac.uk.

* Corresponding author.

E-mail address: mr230@sussex.ac.uk (M. Ramirez).

${ }^{1}$ This includes the United Nations Development Programme “Growing inclusive Markets”: see http://www.growinginclusivemarkets.org/1.

${ }^{2}$ Although not central to this paper, one of the main criticisms Cáceres (2015) makes regarding the expansion of agribusiness is land grab and displacement of lands held by small producers.
} 
We frame the analysis within a typology ${ }^{3}$ of inclusion that lays out four scenarios in a two-by-two matrix, the axes of which are labelled as network bridging (a proxy for openness of the cluster), network bonding (the degree of internal connectedness of local actors) and a parallel measure of small producer participation (or network governance). The discussion and typology act as a guide to an empirical analysis of two agricultural clusters with contrasting experiences of inclusion. These are a palm oil cluster in the municipality of Puerto Wilches in central - north east Colombia and the mango cluster in the Piura area of northern Peru. These geographical clusters share a number of features including similar number of producers, dominant agri-food export industry and the predominance of small-scale producers. Social network analysis is used initially to identify and compare the structure of networks. Because network structure has little to say about governance and the source of new ideas/programs we subsequently use qualitative material to assess differences in governance. We end with illustrative cases of two possible permutations that indicate how different combinations of network structures combine with network governance to affect the development of inclusive agriculture. These suggest that a highly hierarchical and centralized network cluster will be strongly influenced by actor(s) at the centre of the network, and therefore that inclusion dynamics can vary considerably according to behaviour of these anchor actors. By contrast, greater decentralisation of links and small producer self-organisation is associated to sub-networks that, within the confines of narrow protocols and certifications imposed by buyer chains, are still able to follow different strategies of inclusion for adoption and use of technology.

\section{Inclusion of small producers in agri-food: a social network approach lens}

There exists a dominant view amongst agricultural extension practitioners that small producer inclusion in agri-food markets primarily comes down to diffusion of information of practices. The focus lies on codification of top-down systems of knowledge transfer and the propagation of "packages" of new practices and protocols by agricultural extension services to farmers (Morris, 1991). A significant body of academic literature addressing questions of small-scale producer farming in agribusiness reinforces this view, especially in regard to less developed economies. For example, from the natural resource management perspective it is recognized that state-funded extension services will organise technology transfer in a top-down manner (Darr and Pretzsch, 2008; Lahai et al., 1999). Driving these practices is a set of regulations handed down by large buyer firms or national scientific consortiums designed to meet standards of quality that reflect narrow codified protocols. The global value chain literature similarly focusses on the quality of predominantly top-down diffusion of knowledge. For example Dolan and Humphrey (2000, 2004), whilst recognising the efforts of UK supermarkets to achieve a more hands-on relationship with different actors in value chains, suggest greater use of detailed written protocols and procedures for growing, harvesting, processing and transport. Humphrey (2006) and Jan van Roekel et al. (2002) also argue that the initial simple distinctions between buyer-driven and production-driven agribusiness supply chains described in Dolan and Humphrey (2000) has given way to more nuanced relationships between actors in the chain. Nevertheless, within the above accounts local institutions and small-scale producers appear to be fairly passive observers as new practices are introduced by large buyers further up the value chain or by national scientific consortiums.

There is of course an extensive body of literature which has criticized narrow top-down approaches to diffusion and technical change

\footnotetext{
${ }^{3}$ We specifically refer to a typology rather taxonomy because the objective is to put forward ideal scenarios that help develop new approaches to the study of inclusion in agricultural clusters.
}

(Mansuri and Rao, 2013) in agricultural developmental contexts (Clarke and Ramirez, 2014). The critique is that in centralized systems, new practices are introduced and justified on the basis of reductionist discourses of "sound science" (Essex, 2008) that privilege one way linear flows of information from "technical experts" to individual farmers (Rogers, 2010). However, little is said in this account regarding the difficulties of incorporating small-scale producers where the dominant norms for introducing new practices are centralized and topdown.

A difficulty of the debates concerning inclusive approaches in agrifood and agribusiness more generally is that much work is either framed around assumptions that prioritize top-down diffusion of technology that leaves little room for agency of small-scale producers or on micro studies that promote bottom-up participation and democratization processes that can be difficult to achieve in agri-food environments where protocols for production, certifications and food safety standards are inflexible. We are therefore left somewhat unclear about how local contingencies can influence inclusion outcomes.

Yet, some studies show that inclusive paths to incorporation of small-scale producers in Andean agri-business contexts can occur by building local social capital. In particular, detailed case study work by Bebbington (1997) and Bebbington (1998) show how local organisations have, in some circumstances, been able to regenerate rural small farm production by managing, accessing and generating technologies and providing technical assistance to local producers, as well as establishing strong external linkages including negotiating with the state, accessing markets and linking with financial services. These studies are to some extent antecedents to this paper for they set out the importance of social capital and brokers for local development. This paper takes these studies further by developing qualitative and quantitative methodology that allow a more in-depth understanding of the organisational and cluster dynamics. Reflecting on the above critique, we adopt arelational approach that allows us to incorporate both structural and contingent features of local clusters. The basis of our argument is that important inter-cluster differences in inclusion can be analysed from how local patterns of network structure and network governance emerge. Network structure refers to the connections actors establish to receive information and know-how and their position (central, connected or marginal) within this network. The structure of a local buyerdriven agribusiness network is likely to be dominated by large buyers with separate links to suppliers of commodities. Small producers that sell these commodities to local buyers may be scattered or may establish their own social ties and collaborations within a geographical cluster. Therefore we take a broad view of network formation that reminds us that there can be a range of network structures within which patterns of inclusion, social fragmentation and exclusion can exist (Bardhan and Udry, 1999; Bandiera and Rasul, 2006). Network governance on the other hand refers to the nature of the relationships between actors including the degree of participation small producers have in how practices are introduced. Below we lay out the main arguments.

\section{Debating network structure: bonding and bridging}

Social networks (and its associated theory of social capital) has been a recurrent topic of debate and discussion on collective action and development. It became particularly fashionable after the World Bank adopted social capital as a key policy tool in the 1990s to encourage a social agenda to reduce social exclusion and build community capacity (Bebbington et al., 2008). The fact that the delivery of everyday goods and services by the state is non-existent or highly deficient in less economically developed countries means that network type structures such as community groups often play an essential role in public provision (Fafchamps, 2006) which heightens the importance of connectedness. At the centre of our discussion will be different network structures and the relationships (and potential tensions) between 
bonding represented by highly connected actors and bridging that represents open networks that encourage the search for new knowledge and innovation. As discussed below, these two features of networks and the relationships between them appear repeatedly in studies of development.

Network structures can be analysed around two commonly used lenses. At one end is a spectrum composed of dense networks, referred to as "bonding", where social practices are directed to increasing cohesion in communities and practices tend to be more homogenous (Coleman, 2000). Hence participation in the production of common products ostensibly facilitates complementary linkages (Visser, 1999). Collective action that emerges from bonding activity has traditionally played an important role in family agriculture, with authors such as (Schmitz, 1995) arguing that "active collective efficiency'" can overcome the drawbacks of small size and the problems facing small producers emerge more from isolation than size. Coleman (2000) argues that the advantage of bonding lies primarily in the ability to establish and impose common rules and norms because network members have the power to decide who joins and who is excluded and can sanction opportunistic members. This creates a degree of predictability in the behaviour of others and allows greater investment in partners. It is also facilitated through a common bond, such as homogeneity of socioeconomic status.

An alternative view of social networks eschews the advantages of bonding and by contrast extolls the virtues of bridging, which is where information flows between rather than within dense networks. Burt (1992) refers to these as bridging networks that can be exploited by organisations that act as brokers of information flows amongst individual actors. In contrast to the bonding approach, bridging emphasizes to a greater extent the benefits that actors have when freed from tight relationships. This approach therefore emphasizes to a far greater degree the importance of linking to knowledge networks that come from outside the cluster. The key notion here is that highly dense networks can suffer from redundant information and in this scenario, the coordination costs of maintaining a network can outweigh the advantages that might emerge from it. The focus therefore lies in individual actors acting as brokers with access to less redundant information through strategic position in a network. Bridging as a specific division of labour addresses a critical feature of this discussion which is how open, diverse and innovative agribusiness clusters can be and how this diversity can benefit the different parts of the network. Research highlighting the importance of brokering in smallholder agriculture includes Goldberger's (2008) study of scientization of organic agriculture, where brokers were crucial in the legitimization of alternative value chains. A boundary framework is used to understand how negotiation among socially and geographically disparate social worlds has resulted in diffusion of non-certified organic agriculture in Kenya. Giuliani and Bell (2005) also emphasize the importance of brokers to link with global buyers in Chilean the wine sector.

Debates and evidence on bonding and bridging reflect important discussions on the complementarities and possible trade-offs and tensions between building collective action and strengthening social capital for small producers to exercise agency power on the one hand and the potential drawbacks of tight membership rules that can lead to exclusion and inwardness that resists new innovations on the other (Agrawal and Ostrom, 2001; Bebbington et al., 2008; Carter, 1996; Thorp et al., 2005). For example, the argument is made that for openness to occur internal differentiation between producers is required to allow the necessary leadership to evolve and encourage greater openness. Devaux et al. (2009) also makes the point that heterogeneity and the involvement of diverse actors, including not only farmers but also other actors in the value chain (including chefs) played a critical role in collective action for innovation in a case study of the Papa Andina. A balance between bonding and bridging of activities could in theory encourage connectivity and heterogeneity of actors necessary to combine inclusion and innovation (Narayan, 1999; Pelling and High, 2005).
Indeed, Burt (1992) has argued that bridging is interdependent to bonding because communities can have a division of labour that moves between the two. Clearly this is an area that needs empirical analysis to understand more clearly how bonding and bridging are formed.

\section{Network governance: hierarchies, central actors and bottom-up action}

In addition to bonding and bridging, we introduce a third lens to consider how new innovation practices are introduced through the governance of social networks. Isolated from the influence of other contextual factors, information on network structures say little about how inclusive practices are introduced or distinguishes between different modes of introducing new knowledge that can have fundamentally different implications for small producers. The discussion of social networks therefore requires another dimension that picks up on the hierarchy or level of centralization of small producer networks in terms of the roll out, adoption and adaptation of new technologies and practices. This question overlaps with a long and intense debate in the agricultural development literature on preferences for top-down and bottom-up governance for the introduction of new practices. Preferences for top-down practices are inherent in Hardin's (1968) "tragedy of commons" argument that pointed to the tendency towards over-consumption of common resources and Olson's (1965) concerns over free-riding of public goods. Top-down and more centralized implementation of new practices is argued to work best if there are benefits from economies of scale, require high levels of central coordination and where preferences and needs are likely to be more homogenous (Mansuri and Rao, 2013).

Bottom-up initiatives by contrast provide for greater participation of local actors. Highly influential contributions by Hirschman (1970) on collective agency, Ostrom (2015) on common pool resources and Sugden and Sen (1986) on broad-based capabilities emphasize the importance of the poor and marginalised as informed participants to justify decentralized bottom-up initiatives. Bottom-up inspired practices emphasize knowledge that draws from the practical experience of producers and takes into account their interests, hence is more likely to reflect on issues such as costs of purchase and maintenance of technology.

As argued above, agri-food is likely to be dominated by more centralized practices although there can be important local factors that can influence how practices are introduced. Based on the above discussion of bridging, bonding and network governance, in the following section we present a typology that provides hypothetical scenarios of inclusion (and exclusion) of small-scale producers in agri-food clusters. The advantage of different scenarios is that they can help guide the design of future empirical studies.

\section{Building a typology of inclusion of small-scale producers in agri-food}

Our approach is built on the understanding that social networks reflect the cohesive social relationships upon which collective actions are built (Hoff, 2001). Social networks have the advantage of providing a rigorous language for describing the properties of relations and measurable indicators for certain properties that underlie social capital (for example membership of social groups, connectivity, hierarchical relations) (Moody and Paxton, 2009). On the other hand, social capital concepts explain how social networks come to exist and highlight how context shapes relations. The value of this typology therefore is that it moves the narrative on from a discussion of the influence of separate discrete variables (bonding, bridging and participation) to a discussion of the interplay of three variables and its impact in a common space. This allows us to operationalise and contextualise the framework to the cluster level and lays the ground for the subsequent empirical analysis. We also underline the point that this is a typology of inclusion and is 


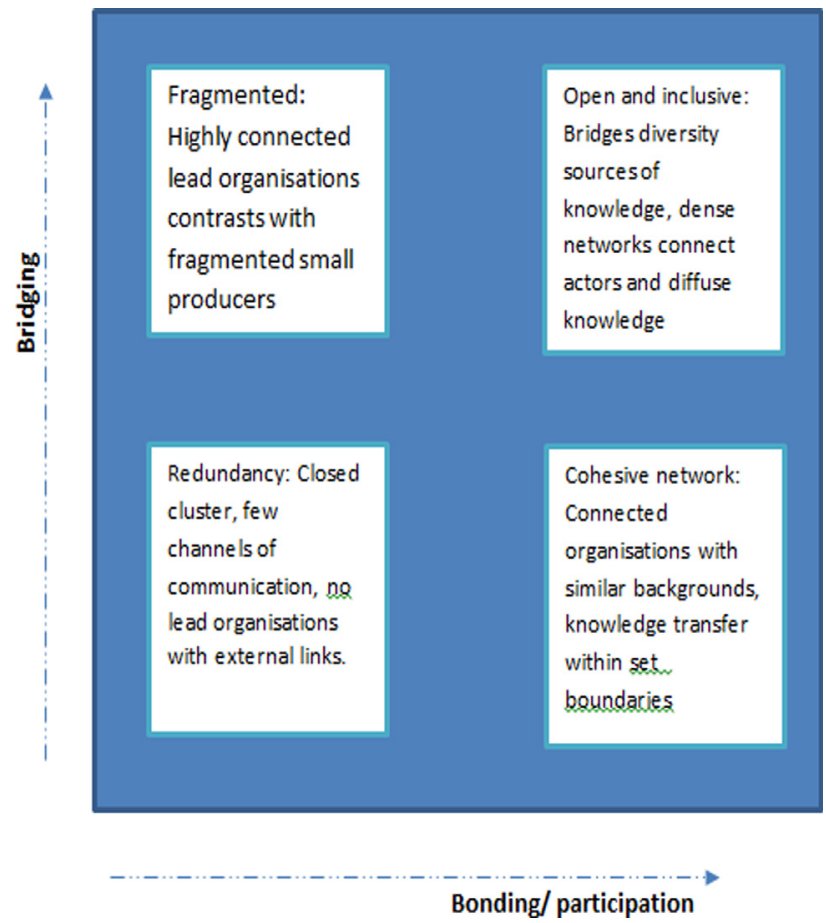

Fig. 1. Typology of social capital and inclusion of farmers.

therefore built from the standpoint of all producers and service organisations and their links within the cluster. This is described visually in a two-by-two matrix in Fig. 1 with three labelled axes that we call bridging, bonding and participation, with values rising as one moves along the axis. Low levels of bridging means the cluster will be relatively closed to diverse sources of new knowledge because there are few knowledge links outside the cluster. This means high levels of redundancy of information within the cluster that could translate into mono production and limited attempts to introduce new practices. Low bridging could also leave the cluster prone to natural-resource crisis such as pests and blights that affect producers because little research is undertaken to combat and keep up-to-date with changing phytosanitary trends. By contrast, high bridging is associated with a range of links from different organisations from outside the cluster and therefore provides greater diversity of knowledge. This may lead to more innovation and experimentation with new seeds, crops and adjustment to local conditions, as well as strategies to reach new markets that require different protocols for production and logistics.

On the bottom axis we place bonding that, as discussed, refers to the degree of connectedness between small producers. High bonding implies that knowledge transfer will be efficient as networks are highly cohesive. Burt (1992) also refers to these highly dense networks as "closure" and suggests that in highly cohesive groups, strong culture and teams can enhance trust and allow reputation to be controlled so that individuals can be trusted to collaborate.

To these two axes we superimpose a governance axis labelled participation, which refers to the degree of collective activity in decisions concerning introduction of new practices. Low levels of participation imply weak small producer representation or independent levels of coordination and a high degree of power and influence in a central administrative body to establish protocols for everything from combatting agricultural diseases or reform of energy distribution systems (Soumonni, 2010). In these cases new technologies or organisational innovations are introduced in a more centralized fashion and power, in the sense of the ability to frame how new practices are designed and used, is more concentrated within certain organisations with high agency power. Top-down practices may also reflect strategies by a large company to oblige smaller producers to adopt specific practices for its benefit in the market, or indeed favour some groups over others. By contrast, with high participation, extensive local discussions will tend to take place regarding new technologies and practices and questions of democracy, sustainability and frugal innovation tend to be prioritised.

Bonding and participation are not identical concepts. The latter is explicitly defined in terms of collective agency power, the former is a feature of a physical network that can emerge for a variety of reasons including a desire to establish solidaristic values that underpin community actions (Thompson, 2003) to enhance capability (Moser, 1998), or as an antidote to vulnerability (Isham, 2002). Nevertheless, it is reasonable to assume that some sort of coherence amongst networks will underpin community action and as (Burt, 1992) suggests, in highly dense networks (or high bonding) a strong collective culture emerges that enhances trust and there is liable to be a closer relationship between actors. Therefore we associated high levels of bonding with higher levels of small-producer participation in the typology. Where bonding is low actors will not be able to act collectively. Formal connections with a lead organisation may exist but is likely to be one-way with high dependence upon one dominant organisation.

Different degrees of bonding, bridging and participation can be thought of as generating distinct scenarios as shown in Fig. 1. We label a cluster that is open with high levels of bridging but low cohesion and weak participation as fragmented. This will occur when some dominant actors have important external and non-redundant ties that bring new knowledge, but large numbers of small producers have few links and limited access to diverse sources of knowledge and there is a low tradition of community engagement. This may give way to new practices being introduced with little discussion and can create a polarisation between the larger producers that are well-connected to agribusiness networks on the one hand and smaller producers reliant on single connections with narrow bandwidth on the other. The network architecture may be visualised in terms of a "hub and spoke" structure with a central organisation linking small producers in one-to-one type links. Diffusion can therefore be rapid but learning may be through imitation and with limited scope for local discussion. This is typically the case when implementing norms set by outside bodies to open export markets, such as detailed by Carbajal and Hernandez (2008) in the Mexican avocado sector where discussions tended to be limited to implementation of fixed protocols and technologies defined by outside actors. In this segment there may also be clusters that are in the early stages opening up to markets. For example Heller and Isaac's (2003) account of a participatory programme in Kerala stressed the efforts to bring the community together by encouraging certain more democratically aware citizens to engage in civic activities that resulted in better local government. This was a precursor to the establishment of working committees and village meetings that increased participation.

A network showing high bonding, low levels of bridging and high participation we label as a cohesive network. High network cohesion knits actors together and practices can diffuse widely. Key service organisations will focus on bringing together fragmented actors and creating infrastructures that can serve as a basis for common action. However there are limited opportunities for exploration because of a lack of bridgers and introduction of new ideas from outside is given a lower priority. Thus it is likely that most of the efforts of the lead organisations involve protecting connected producers from information inconsistent with what they already know. Links tend to be established between actors with similar backgrounds, which lowers risk, reduces exposure and therefore assumes knowledge transfer within a set boundary that could be a geographical area. In this scenario, lead organisations (whether large single producers or representatives of collectives), will tend to use their authority to strengthen collective actions. High bonding therefore suggests (but doesn't necessarily represent proof of) a community where activities and learning are based on strong common norms. But without brokers, practices may well be inward looking and focus on existing experience. McDermott et al. (2009) description of the San Juan wine cluster in Argentina showed 
Table 1

\begin{tabular}{|c|c|c|}
\hline & Mango & Palm Oil \\
\hline Size & $\begin{array}{l}\text { Omitting one large outlier producer, the average size of PROMANGO } \\
\text { producers is } 51 \text { ha and } 124 \text { for APEM members }\end{array}$ & Ranges from 7 to 26 ha with an average of 9 ha \\
\hline Employees & $\begin{array}{l}\text { Just } 5 \text { out of } 26 \text { producers employs less than } 10 \text { people, although work is } \\
\text { seasonal }\end{array}$ & Mostly family. Some employees hired that live locally \\
\hline Market & 16 out of 26 producers sell product in international markets & $\begin{array}{l}\text { Oil palm bunches are sold in local market to processing mill. E1 is the only } \\
\text { processing mill represent in this sample }\end{array}$ \\
\hline Certification & 18 producers are certificated by GlobalGap, 4 have Tesco TNC & $\begin{array}{l}\text { The most recognized certification is given by the RSPO (Round on Sustainable } \\
\text { Palm Oil). Few oil palm growers certified }\end{array}$ \\
\hline Other livelihood & Some attempt to diversify to grape production & $\begin{array}{l}\text { Most small farmers combine a small amount ( } 2 \mathrm{ha} \text { ) of traditional products } \\
\text { (banana, plantain, cassava, and corn) with palm oil }\end{array}$ \\
\hline
\end{tabular}

that despite the existence of high social capital, the lack of cross cutting ties between different social and producer communities limited broadbased learning. Hence redundancy and lock-in is possible. Where both brokerage is low and communities are largely fragmented there is a dearth of opportunities and/or capabilities amongst local actors to attain these.

We characterise a scenario of high openness to external ideas and broad based inclusion as an open and inclusive cluster. This scenario is where high bonding connects actors and bridging creates links to new sources of knowledge. High rates of social participation means some adaptation of new practices and technologies in response to small producer requirements takes place. An example could be McDermott et al's (2009) study of the Mendoza wine cluster, where bridging roles are played by government support institutes such as public research labs and training centres that are also committed to deliver collective resources. Devaux et al's (2009) study of participatory market chain model and stakeholder platforms in the Andean potato similarly showed how small farmers were able to achieve high levels of organisation with the benefit of researchers and other service providers to experiment in finding new markets from existing varieties. New relationships are encouraged and built within the context of stability of existing ties, but high levels of social participation ensures there is extensive local discussion and efforts are made to ensure the involvement of small producers and their organisations. Social capital exists alongside opportunities for learning and innovation. Because there is high levels of participation, shared use of technology is often favoured by small producers as a means of lowering costs.

Finally, we label a cluster where networks are typically fragmented and there is little scope for brokerage opportunities as redundancy. This could describe a mature agribusiness sector or isolated area where there exist few opportunities for new markets and few lead organisations able to support isolated communities in the development of capabilities. Participation will be limited and practices often not suited to the needs of smaller producers. The absence of collective initiatives means some actors will typically remain marginalised and large inequalities can be locked in.

\section{Methodology}

Fig. 1 poses a series of ideal-type scenarios of small producer involvement in agri-food knowledge networks. We proceed to present and discuss two empirical studies cases of clusters in developing economy contexts guided by the above typology. The case studies are based on the palm oil cluster in the municipality of Puerto Wilches in north east Colombia and the mango cluster in the Piura area of Northern Peru. These geographical clusters share a number of features, but also show some important structural differences.

Table 1 provides details of some of the main characteristics of each. Small and medium-sized (rather than micro) producers represent the majority of growers in terms of numbers of producers and as a proportion of total production in the cluster. Definitions of what is small, medium and large are important. However, we draw on Fernandez- stark et al. (2012) who view that size is a heterogeneous concept because beyond the physical size of land, producers have different levels of access to services and water. In our case we also distinguish producers through their reliance on larger producers for access to markets. Both clusters are highly labour intensive with limited possibilities for mechanisation but there is buoyant demand for these products in national (palm oil) and international (mango) markets. However the clusters also resemble aspects of what Altenburg and Meyer-Stamer (1999) have called survival clusters that suffer from poor entrepreneurial competence and a dearth of management skills.

The palm oil cluster began production through the creation of a palm oil refinery firm in 1961, whilst export production for the mango began in the 1990s with the establishment of key service organisations and producer associations. As Table 1 shows, the mango producers have two main associations, APEM and PROMANGO. The latter represents the smaller producers with an average size of 51 ha. By contrast, in the palm oil all but one of the producers has a smaller scale of production with an average size of 9 ha.

The unit of analysis is the geographical cluster since physical proximity plays an important role in knowledge networks. Two sets of identical surveys were used, one for producers (17 in the palm oil, 26 in the mango cluster), and one for service organisations ( 9 in the mango cluster, 5 in the palm oil). Analysis of survey data was undertaken through social network analysis (SNA) techniques that permit visualization and measurement of the structures of relationships and the strategic of positioning of actors in these relationships. The survey data was gathered in both clusters through identical face-to-face surveys. The question asked to firms was: "from whom did your organisation (or business) receive technical assistance for the introduction of new practices and/or technologies and how important was this to your organisation"? ${ }^{4}$ Respondents were provided a list of organisations (producers, services, universities, consultancies) and an open section to name other organisations from whom assistance had been received and to then identify and rank organisations from whom assistance was received from 1 to 5 in ascending order of importance. From this information it was possible to produce a network map using open source software, Pajek for social network analysis.

The subsequent analysis of network governance was investigated through in-depth semi-structured interviews of actors in both clusters. Qualitative data in the palm oil cluster involved two interviews with small farmer representatives, two interviews with executives of large palm oil companies, and shadowing of CENIPALMA R\&D and field staff. Group discussions also took place with high level officials of CENIPALMA and FEDEPALMA (Colombian palm oil's two linked representatives).

In the case of the mango cluster, twenty semi-structured interviews took place with owners of small and medium-sized mango firms and directors of the main intermediaries including APEM, PROMANGO, and several government agencies with offices located in Piura. The producer

\footnotetext{
${ }^{4}$ This wording is similar to that used by Bell and Giuliani (2007) in her study of knowledge networks in the wine industry.
} 
association congresses of APEM and PROMANGO were attended and detailed notes made as observers.

\section{Agri-food and social capital}

Existing literature on social capital and small holder participation in agri-food in developmental contexts, including Andean contexts suggests that common practices and community action are driven by two factors, access markets and addressing exclusion. The former camp includes the work of Hellin et al. (2009), Hartwich et al. (2008) and Liverpool-Tasie and Winter-Nelson (2012) who all emphasize that greater product differentiation and complexity of products as well as high transaction costs to enter markets increases the likelihood of collective participation and networks (and social learning) amongst small holders. Other studies find that even where the product has low transaction costs, small producers can still gain advantages from collective organisation in terms of for example bulk-buy and securing access (Devaux et al., 2009; Hartwich et al., 2008; Kherallah et al., 2002; Thorp et al., 2005).

A rather different explanation for the existence of social capital is presented in other studies where the focus is on the properties that bond together communities facing asymmetries of knowledge from powerful actors. Bernard and Spielman's (2009) work on poor farmers in Ethiopia showed that low participation rates of the poorest farmers had little to do with lack of material interests, but that they were often excluded from decision making. This finding is in line with Thompson and Scoones (1994) who argue that agribusiness involves encounters between organisations with varied interests, supported by different resources and relations of power. Therefore a critical reflection of farmerresearcher-extensionist relations should be in terms of equity of relationships and biases of actors.

The significant feature of the above discussion is that quite contrasting narratives of social capital seem to co-exist. The literature tends to favour one or other approach in its methodology although in practice they influence one another, such as in the emergence of alternative organic or fair trade value chains. The two cases discussed in this paper represent undifferentiated products at the point in which small producers work with them. Capacity is important but occurs higher up the value chain in preventative measures to reduce blights, certification and ensuring delivery of good quality produce.

The Colombian palm oil is dominated by three specific features. The first is the growing importance of small-scale producers as a proportion of cultivated land in the industry. ${ }^{5}$ This has come about following a government and United Nations sponsored programme of land distribution titled "Productive Alliances" to provide small-scale farmers with alternatives to growing illicit drugs. Ten years ago large firms purchased (from small holders) just $30 \%$ of the fruit for refining, in 2010 this jumped to 70\% (Cordoba, 2011), therefore their relationship with small producers is critical for accessing regular supply.

Secondly, the sector experiences excess demand, firstly as a consequence of the rise in domestic demand of palm oil for use as a bio-fuel and secondly as consequence of the spread of the Pudricion del Cogollo (PC), (translated but root disease) an airborne disease affecting tropical areas that has wiped out large numbers of palm trees. Large resources have been devoted to prevention measures against the PC and its treatment by CENIPALMA. Two prominent approaches include the replacement of the indigenous Colombia palm tree by the "African palm", a hybrid, that is hoped will be more resistant. The second approach involves agricultural practices (maintenance of hydration infrastructure and weed control) and plant disease treatment (combination of fertilizer, pesticides and insecticides).

\footnotetext{
${ }^{5}$ There are three classifications of farm size in the palm oil sector: large growers (more than $500 \mathrm{ha}$ ), medium-sized grower (between 50 and $500 \mathrm{ha}$ ) and small sized growers (less than 50 ha) (Roundtable on Sustainable Palm Oil, 2013).
}

The third feature is the industry organisation in the rural areas. Small farms tend to geographically cluster around large refinery palm oil plants in so-called UATTAS. The land surrounding the refinery is owned partly by the refinery firm and partly by small producers called "allies" who sell the basic produce to the larger refinery. Physical proximity between the producer of palm oil and refinery firm is crucial to maintain freshness. There are therefore two key organisations at the centre of each cluster, a refinery firm and in some cases a small producer association.

Studies of palm oil in Colombia however also need to take into account what can be quite contrasting local histories and patterns of social capital can vary significantly at regional and local level. In a number of areas such as Cano Seco, Tamboral and Arenales in the south west, and Bajo Ataro in the northwest of the country, so-called "new entrepreneurs" took up palm oil production in the 1980s and 1990s in zones affected by the conflict with armed guerrilla forces. Lands were "cleared" for palm oil production through the displacement of farmers with the help of paramilitary forces (Vidal, 2011). In other regions, including the central parts of Colombia, that is the focus of this study, small holders have a longer history of involvement combining contract farming, spot price sales and as agricultural labour. The take up of national initiatives such as the Productive Alliances has been generally well received, particularly since many farmers do not have access to land and are therefore likely to be framed through opportunities for productive activity.

The structure of the mango cluster in Piura resembles the palm oil in terms of the numeric dominance of smaller and medium sized producers (see Table 1) and the production of a single agricultural commodity. Piura is one of the Peru's country's most important agricultural regions. Post-war investments from the World Bank in water storage and management helped overcome the challenges of an arid climate, although export of mangos only began to increase significantly in the 1990s when the first hot water treatment plant was installed.

However, the end of the 1990s also witnessed an important conflict between actors involved in agriculture and Canadian mining firms, such as Manhattan Minerals of Canada in the Tambogrande region of Piura. The mining project, as well as its requirement for significant human resettlement posed large-scale appropriation of agricultural land, potential to pollute adjoining areas and displacement of farmers. The project, eventually abandoned in 2003, prompted coordinated opposition from parts of civil society including urban residents, market-oriented modernizing farmers and a rural peasantry (Bebbington, 2012). The experience and in particular the social mobilization behind it, cemented a regional commitment to investment in agri-food as an activity that would be likely to have more positive effects for the local population. This experience showed the ability to establish temporary local alliances, although tensions between producers with access to export markets and those without access appear again through the existence of the two producer associations in the region, APEM and PROMANGO. APEM represents organisations combining exporting and production whilst PROMANGO, formed after a collapse of prices in 2002, represents smaller-scale producers. Members of both associations make up around $30 \%$ of growers and $60 \%$ of production and form the centrepiece of the study. Other key organisations at local level include SENASA, the phytosanitary government body and other service organisations play important roles. A key competence is reaching certification standards necessary for exports, combating fruit plagues such as fruit fly, incorporating a greater control and improvement in the detail of production processes and technologies and establishing good networks with a range of buyers from different export markets.

\section{Analysis of network coherence}

We begin the empirical analysis of network coherence that provides information on the degree of connectedness of producers. Figs. 2 and 3 below provide an illustrative overview of the network of both clusters. 


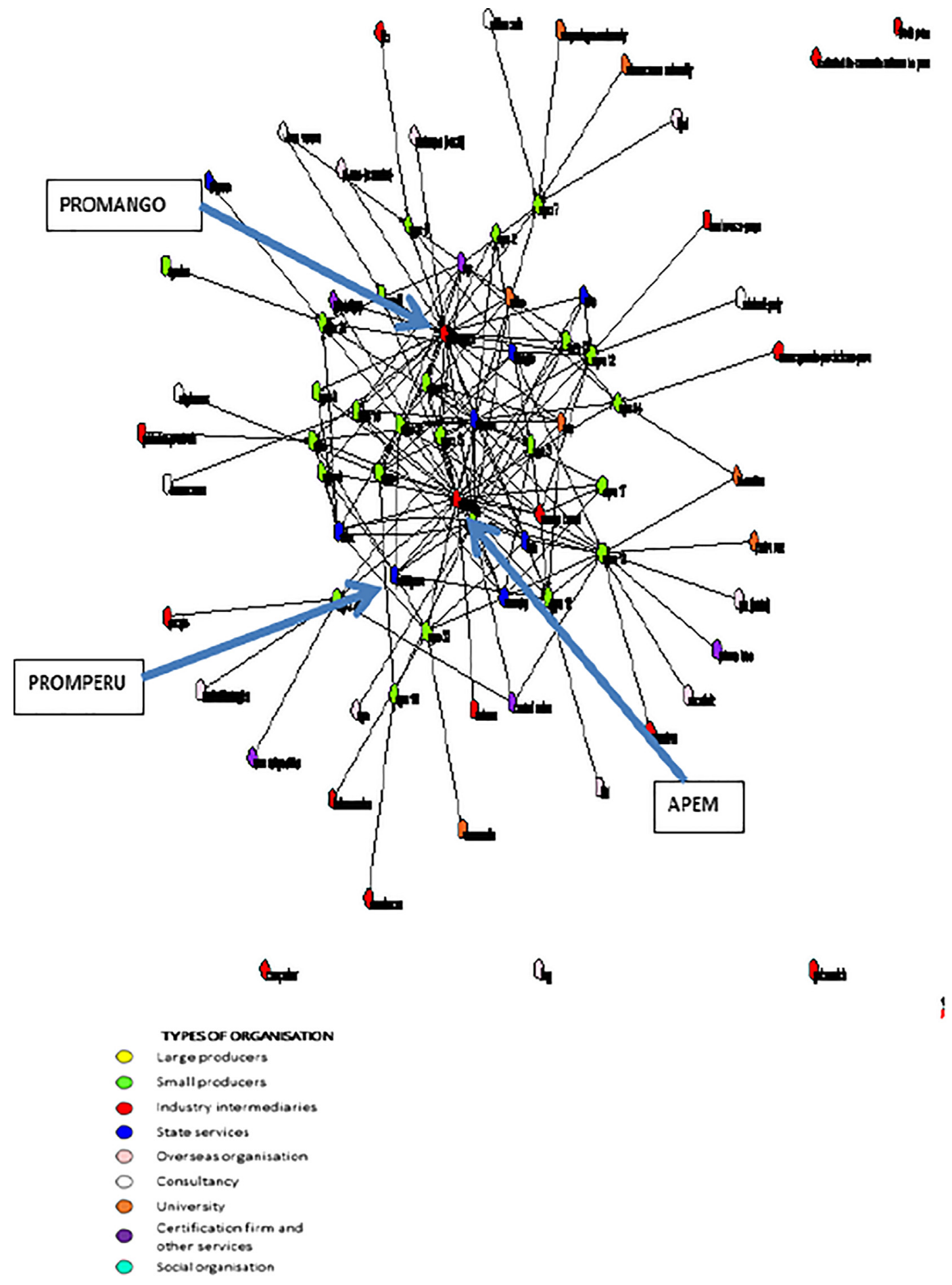

Fig. 2. Social Network Analysis Map of the Mango Cluster.

Small producers are denoted with the prefix "agro" and all actors are coloured differently according to the type of organisation and their function in the clusters. If we include the organisations mentioned by the interviewees as providers of knowledge (i.e. not all those interviewed), the total number of mango cluster and the palm oil organisations in each cluster number 75 and 37 respectively.

Figs. 2 and 3 shows the network maps of the mango and palm oil clusters. The mango cluster appears as a highly-connected group of producer firms at the core of which are a group of service providers. The palm oil cluster illustrates a simpler hub-and-spoke structure with small producers clustered around E1, a large local producer and refinery firm that is supplied palm oil by the surrounding small farmers and CENIPALMA, the technology research arm of FEDEPALMA, the national producer association. Although CENIPALMA formally represents national palm oil producers, it is mainly influenced by the larger organisations that provide most of its funding. Although both networks appear highly centralized with limited connections between organisations at the peripheries, the mango cluster has more producers and services at the centre of the network.

Table 2 describes the organisations and actors in each cluster. It is notable that although there are no large organisations in the mango cluster, there is more heterogeneity of organisations reflected in higher 

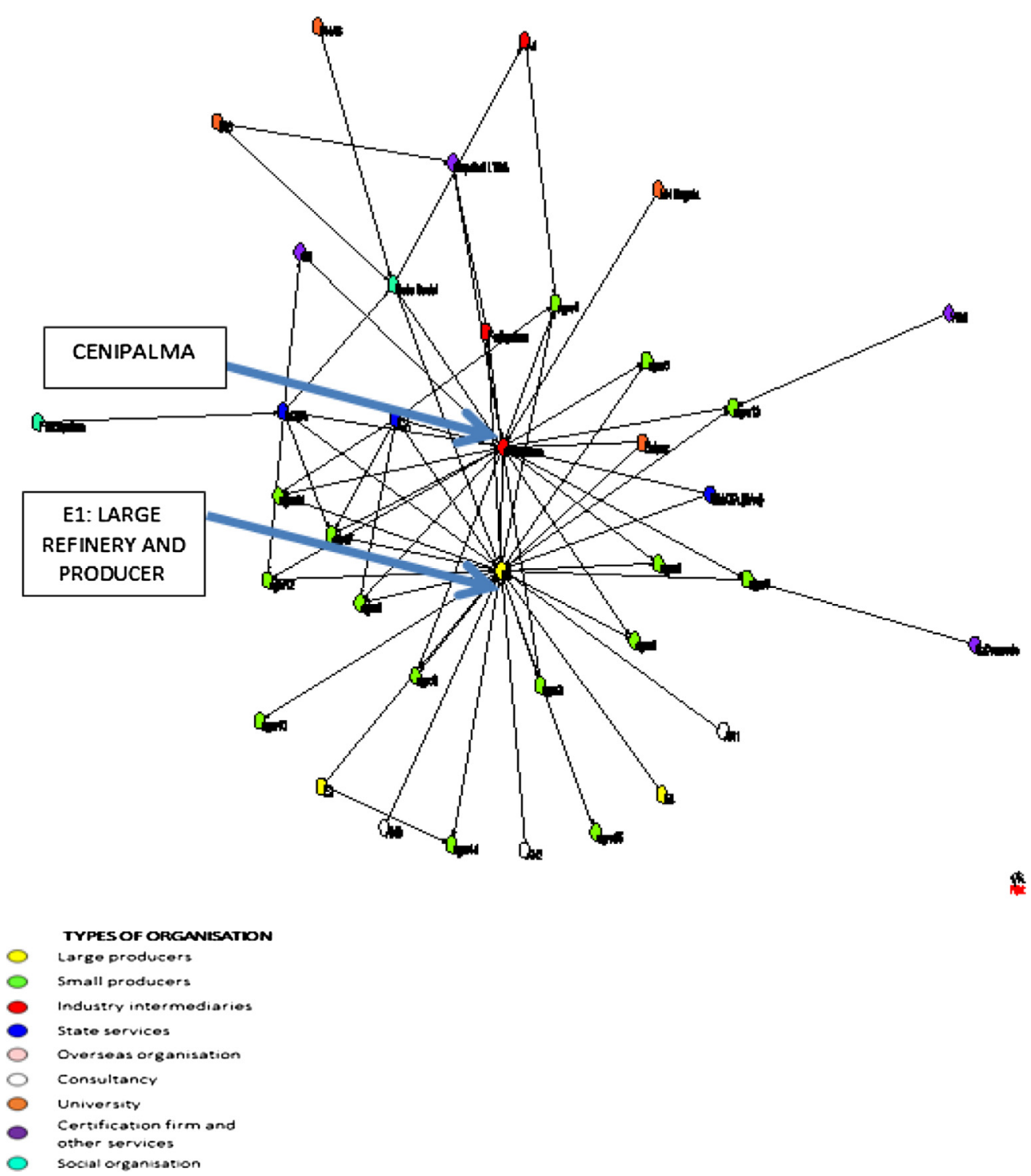

Source: Calculated from author survey of mango producers

Source: Calculated from author survey of palm oil producers ${ }^{4}$

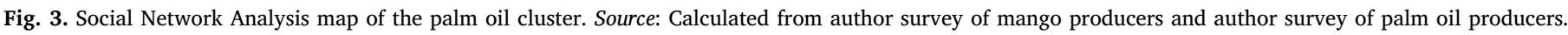

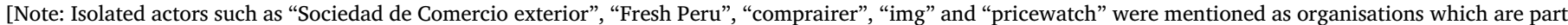
of the network but whose knowledge transfer was considered "unimportant" by the interviewees.]

numbers of intermediaries, government services and universities that provide knowledge to the cluster.

We use K-core method that allows observation of the number of links of all the vertices within the cluster and if any dense sub-networks exist to analyse bonding. Table 3 below shows mean average k-core values of 3.35 and 2 for the mango and palm oil cluster respectively indicating significantly higher levels of bonding in the mango cluster. Moreover, the distribution in the mango cluster is skewed towards higher values ( $64 \%$ of palm oil firms have just two links, $50 \%$ of mango firms have four links) meaning that a significant majority of small farmers in the palm oil are reliant on just one or two channels of information. K-core also allows detection of dense sub-groups by removing the lowest $\mathrm{k}$-cores from the network until this breaks up into dense components (de Nooy, 2011). With values of one omitted (i.e. we just include values 2 to 5 ) Fig. 4 shows the palm oil network becomes very sparse at K-core equal to five and is reduced to just two organisations at K-core equal to ten. In other words very few actors have many links. The mango network by contrast shows five organisations at K- core equal to ten and three organisations at twenty. Although the palm oil growers are therefore formally connected, the number of connections is very sparse and dependent on just two organisations with a high number of links. By contrast within the mango cluster a number of organisations have up to ten or higher links. We can conclude that average bonding is significantly higher in the mango cluster but also that there are different hubs within each cluster.

And yet, a more detailed analysis of bonding in the mango cluster also reveals patterns of structural fragmentation hidden by average values of connectedness. K-core analysis reveals that there is no direct line of communication between APEM and PROMANGO the two most prominent organisations. Moreover, very few small-scale producers receive information from APEM and exporters from PROMANGO. Given their central positions as representative associations this suggests asymmetric information between the exporters association (APEM) and small producers (PROMANGO).

In terms of bridging, we can refer to structural holes values that measure non-redundant information flows. Table 3 indicates high 
Table 2

Source: Based on authors survey of palm oil and mango clusters.

\begin{tabular}{|c|c|c|c|c|}
\hline \multirow{2}{*}{$\begin{array}{l}\text { Types of } \\
\text { Organisation }\end{array}$} & \multicolumn{2}{|l|}{ Palm oil } & \multicolumn{2}{|l|}{ Mango } \\
\hline & $\begin{array}{l}\text { Number of } \\
\text { actors by } \\
\text { organisation }\end{array}$ & Percentage & $\begin{array}{l}\text { Number of } \\
\text { actors by } \\
\text { organisation }\end{array}$ & Percentage \\
\hline Large producers & 3 & $8 \%$ & 0 & 0 \\
\hline Small producers & 15 & $41 \%$ & 26 & $35 \%$ \\
\hline $\begin{array}{l}\text { Industry } \\
\quad \text { intermediaries }\end{array}$ & 3 & $8 \%$ & 15 & $20 \%$ \\
\hline State services & 3 & $8 \%$ & 8 & $11 \%$ \\
\hline $\begin{array}{l}\text { Overseas } \\
\quad \text { organisation }\end{array}$ & 0 & $0 \%$ & 9 & $12 \%$ \\
\hline Consultancy & 3 & $8 \%$ & 5 & $7 \%$ \\
\hline University & 4 & $11 \%$ & 7 & $9 \%$ \\
\hline $\begin{array}{l}\text { Certification firm } \\
\text { and other } \\
\text { services }\end{array}$ & 4 & $11 \%$ & 5 & $7 \%$ \\
\hline Social organisation & 2 & $5 \%$ & 0 & $0 \%$ \\
\hline Total & 37 & & 75 & \\
\hline
\end{tabular}

reliance in both clusters on a small number of organisations as conduits of knowledge. However this measure doesn't distinguish bridging from inside and outside the cluster, knowledge from outside is likely to open the cluster to new ideas. To do this we look at averages of indegree centrality from outside the cluster. In table 3 we can see that this differs significantly between the clusters, confirming that in the palm oil there is just one organisation that maintains significant links outside the cluster. The mango cluster by contrast shows more complexity in its structure with a greater variety of organisations acting as bridgers that include private producers and service providers. The data indicates that the mango cluster is more open to diverse knowledge.

A revealing phenomenon appears if we compare indegree centrality from outside the cluster with outdegree centrality, i.e. organisations involved in bridging and bonding. Although we saw in the mango cluster that a number of organisations are active in gaining knowledge from outside the cluster, Fig. 5 shows that the privately owned organisations do not appear to be sharing this sharing knowledge, even with their associations (for example agro 21). Only the state-run phytosanitary body, and the producer associations are involved in collective dissemination. Private firms in the mango cluster are more likely to maintain knowledge in the private sphere. This contrasts with the palm oil, where a single privately owned organisation refinery E1, acts as bridger and bonder, articulating the network of small producers (see Fig. 5).

Summarising the results of network structure we find that the in the palm oil cluster there are few lead organisations and therefore bridging values are lower. Low bonding reflects high reliance on a lead organisation through a simple hub-and-spoke type network structure. The mango cluster shows higher levels of bridging and bonding. The higher numbers of intermediary organisations help increase bridging values whilst some producers have broader links within the cluster. However there is also a more complex network structure with a sub groups represented by exporters and smaller producers. The establishment of separate networks may reflect homophily, a concept developed to explain why actors with similar characteristics (for example geographical, socio-economic, cultural) tend to stick together to form networks (McPherson et al., 2001).

\section{Case study interviews: bridging, bonding and governance}

As expected, the analysis of network structure within our two case studies established contrasting scenarios although governance in both clusters is characterised by top-down centralisation of practices. As discussed, the dominant narrative in the palm oil centres on containing the devastation caused by the spread of the pudricion de cogollo (PC) disease. Technicians based in the palm oil refinery firms at the centre of each cluster are responsible for diffusing know-how to surrounding small-scale producers. Therefore practices emanate in a hierarchical top-down fashion from established firms and attempts to reinterpret the design of the scheme are not encouraged. Officials of CENIPALMA further commented that convincing small farmers to undertake training in recognising PC and to keep detailed records and take appropriate measures is critical. Opportunities to access knowledge also depend on the nature of the engagement and leadership provided by the organisation at the centre of each cluster.

The interviews allowed us to differentiate two modes engagement that could be described as paternal and reluctant modes of engagement. Paternal engagement is represented by a dominant central organisation - in this case a large refinery firm - that steps in to assist small farmers in the adoption of new techniques. However, in a neighbouring cluster with very similar characteristics, the interviews suggested that the large producer expends few efforts to establish effective channels of diffusion and refinery firms haven't got the authority over small producers to make them follow certain practices.

A CENIPALMA official comments:

"There are some nucleos where the leading company is only really interested in buying the fruit, it is not interested under which conditions this is produced, but there are cases ... where the whole sanitary scheme is run by the anchor firm. So in some places it is working in others it hardly exists".

Relations between large and small producers appear to reflect the ongoing pragmatism of small farmers in Colombia towards both subsidies from the state and alliances with refinery firms, particularly given the limited ability of small farmers to influence practices.

Rather than dependence on one private producer, the mango cluster's network identified a number of organisations with different governance structures at the centre of the cluster, although two producer associations wield significant agency power on behalf of their members. Network analysis also identified two sub-structures represented by small-sized producers, with their representative association

Table 3

Summary results of social network analysis.

Source: Calculated from author survey of palm oil and mango producers.

\begin{tabular}{|c|c|c|c|c|c|c|}
\hline & & \multicolumn{2}{|c|}{ Palm Oil } & \multicolumn{2}{|c|}{ Mango } & \multirow[b]{2}{*}{ Independient sample $t$-test (Sig. 2-tailed) } \\
\hline & & Mean & Std deviation & Mean & Std deviation & \\
\hline \multirow[t]{2}{*}{ Cohesion } & Indegree from within cluster & 2.06 & 0.827 & 3.85 & 2.073 & 0.000 \\
\hline & K-Core & 2 & 0.612 & 3.35 & 0.745 & 0.000 \\
\hline Brokering & Structural holes (betweeness centrality) & 0.39 & 0.21 & 0.66 & 0.12 & 0.000 \\
\hline Openness & Indegree from outside cluster & 0.88 & 1.9 & 2.85 & 2.014 & 0.025 \\
\hline Degree of sharing & Outdegree centrality & 1.86 & 5.81 & 2.94 & 4.46 & \\
\hline
\end{tabular}

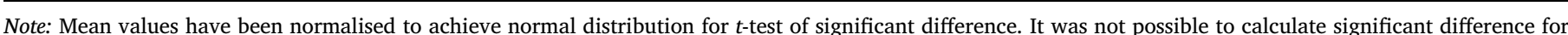
"outdegree centrality" because too few organisations in the survey share knowledge. 


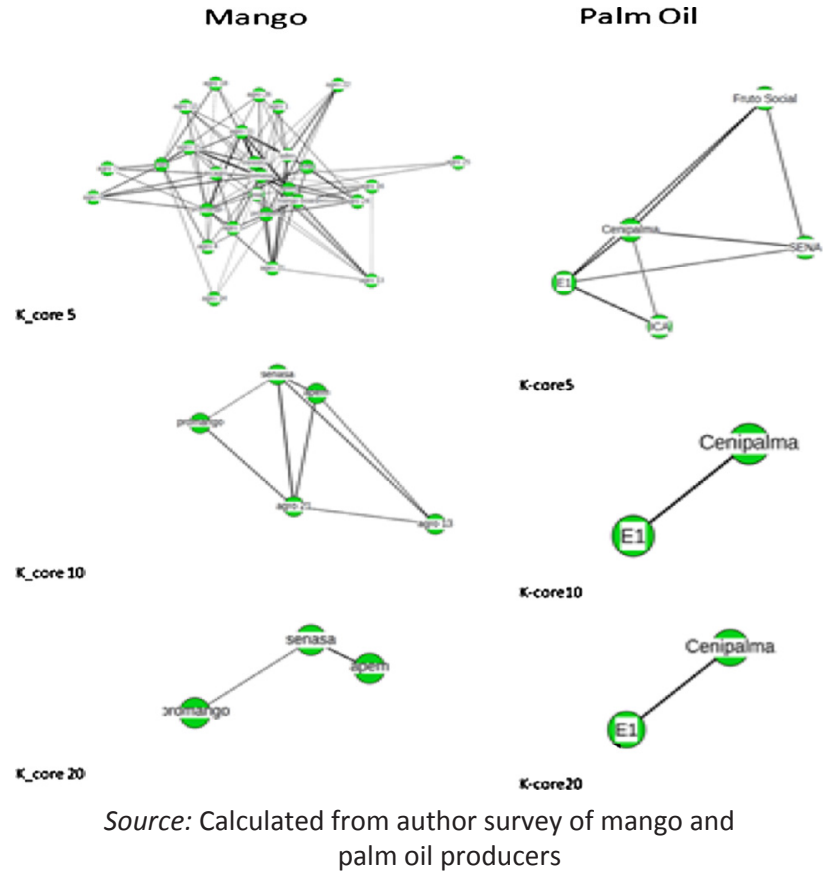

Fig. 4. K-core value.

Source: Calculated from author survey of mango and palm oil producers.

PROMANGO at the centre and larger exporters with APEM at the centre.

Our interviews suggested that these sub-structures are underpinned by fundamentally different approaches to the adoption of technology. The community of exporters around their association APEM is brought together to maximize exports and insertion in markets. APEM plays a strong brokering role by providing its members intelligence on prices in

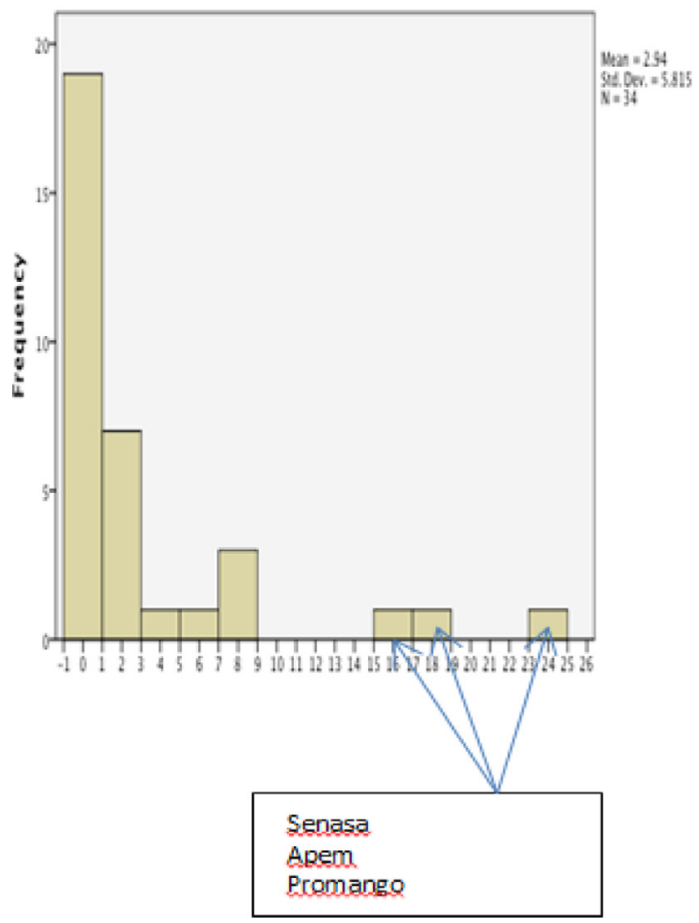

international markets, bringing in external experts for export certifications, opening up new export markets (currently in Asia) and establishing research partnerships with local universities. Implementation of day-to-day practices is largely the responsibility of individual firms that can hire agronomers to manage production.

The PROMANGO association by contrast is overwhelmingly focused on the day-to-day practices of its members such has improving yields, encouraging best practice in the use of fertilizer, treatment of trees, storage and transporting. Its annual congresses resemble a community of practice as producers gather to share experiences. Choices regarding new technologies, such as the purchase of a hot-water treatment plant (required for exports) and diversification into grape and cacao production are discussed thoroughly at the congresses and the technology is shared by all members. The funds to buy capital and training are raised jointly. Smaller producers therefore can influence practices and technology through their independent representations.

PROMANGO officials recognized the need to transfer technologies and other competences with APEM and exporter firms for certification and to agree prices and acknowledged the need to strengthen the value chain. Nevertheless, as Figs. 3 and 4 showed, although some important firm-to-firm collaborations exist, there are few direct lines of communication between the two associations. As a PROMANGO official stated:

"From APEM we receive nothing in terms of technological knowledge, a little bit of commercial information sometimes, such as databases of exporters, I'd give then one on a scale of one to five".

The sub-networks therefore reflect the direct access to export markets that members of APEM enjoy and PROMANGO don't. This creates asymmetry of power between small-scale producers and exporters in the value-chain. Larger exporters are also often accused of delaying payment to small producers and can charge high packing prices. However, as indicated, there are also fundamentally different normative values between these sub-networks groups which feeds into different ways of using technology. APEM emphasizes individual entrepreneurship and developing the Piura region as a marketing brand.

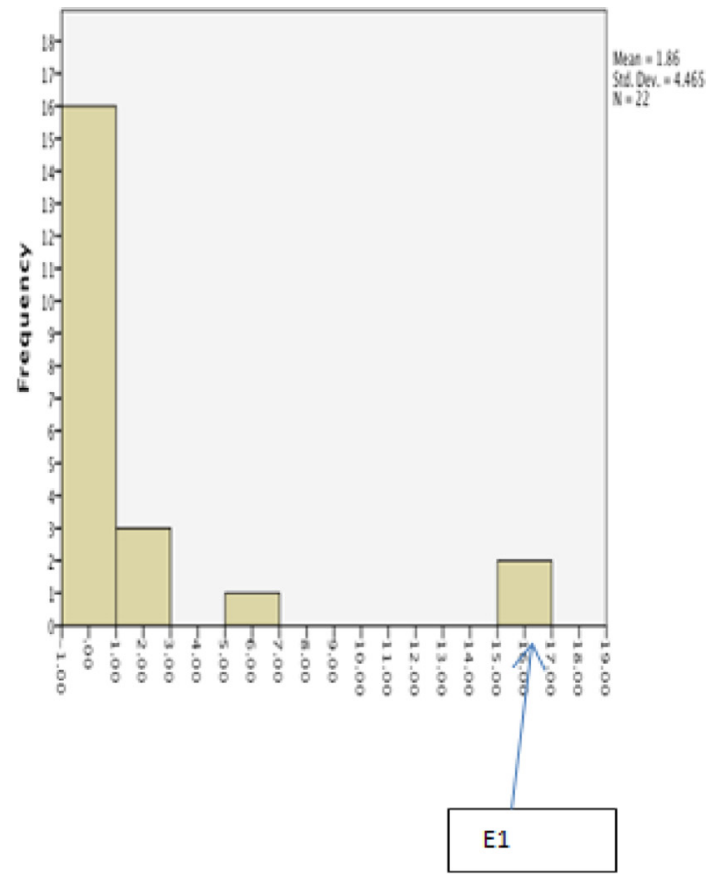

Source: Source: Calculated from author survey of palm oil producers

Fig. 5. Outdegree centrality.

Source: Calculated from author survey of palm oil producers. 
These are critical in determining the costs required to gain entry into export markets. As the APEM president noted:

"APEM is defined by entrepreneurship, there are other institutions that play a more social role, and can help the smallest producers, but our members hardly intervene in this".

PROMANGO by contrast prioritizes solidarity and collective actions, where the needs of farmers and their families and communities guide strategies and choices of technologies.

In summary, the mango cluster reflects important features of an open and inclusive cluster. There are significant relationships between structure and governance. High levels of bridging are encouraged by small producer collective action which creates a demand for services that are different to those of the large producers (for example technologies that can be used collectively). Despite few bilateral peer-topeer links between producers, higher levels of bonding is also explained because of the different intermediaries. Producers have access to more service organisations and groups of producers have their own representative organisations.

Summarising, our two case studies appear in different parts of our typology. The palm oil cluster shows features of a fragmented cluster with one or two organisations at centre with external links. Low levels of bonding reflect absence of collective action and bilateral links by small producers. Different factors may explain this including geographical dispersion of producers and the absence of coordinating organisations such as producer association or NGOs. Collective action may also be discouraged by closing down opportunities for alternative practices.

\section{Discussion and conclusions}

Despite both clusters being dominated by highly centralized protocols for production, our approach allowed us to detect different narratives and practices of inclusion resulting from differences in networks and governance relationships. Two dominant patterns of inclusion were initially identified with the help of our typology and case studies. In the palm oil cluster a relatively fragmented cluster appears with few bilateral links between small producers and high reliance on a central actor, without whom the entire network would collapse. The impact of such dominant organisations is uncertain. Large local organisations can shepherd a community towards positive collective outcomes, for example by setting up experimental sites that can facilitate a process of learning-by-watching (Rao and Ibáñez, 2005). These can lead to highly rapid and efficient diffusion of information. Nevertheless, in highly dependent environments, dominant organisations may also coerce small-scale producers into outcomes that are less favourable for them. We also describe the mango cluster in Peru as "open and inclusive", where top-down protocols for certifications and quality requirements combine with a search for new knowledge based on norms of participation that more closely respond to small producer needs such as sharing technology. However knowledge asymmetries are evident between larger and smaller producers.

We conclude with two linked points. We firstly revisit the point made at the beginning of the paper concerning local (cluster) dynamics. It is clear that social capital dynamics can strongly influence types and forms of inclusion of small producers in agri-food clusters. Therefore, whilst the introduction of agri-food value chains has detonated possibilities (including local alliances) for the establishment of new networks to penetrate markets, these are layered on to highly localised historical and contextual factors that build in structural tensions and exclusion. The paper therefore challenges some conceptions of technology diffusion where formal adoption of agricultural technologies or crop management practices is synonymous with innovation opportunities and benefits for all actors (Roeling, 2007; Rogers, 2010).

Secondly, we address a perceived gap in work on spatial analysis of inclusive innovation in agribusiness clusters identified by for example Fafchamps (2006) and Bebbington et al. (2004) through the use of a diagnostic of network structure. Network analysis can provide exact measurable qualities that underlie the dynamic social processes of interest to social capital as well as facilitating specification and testing. However, social networks does not always overlap with social capital (Moody and Paxton, 2009). Thus the structural cleavage of the mango network was a critical point, but could not be understood through small world's type approaches of Barabási (2003). Qualitative social capital analysis was required to clearly express the close relation between social capital and social embeddedness i.e positive feeling about associationalism or shared values (Moody and Paxton, 2009). By contrast, in the palm oil cluster it was the hierarchical nature of the network and how the agency of the refinery firm was expressed that appeared critical to technology diffusion for small producers. The implications of our approach are double, information on structure provides important insights into the properties of relations but ignoring the context of networks will provide only a partial picture. Therefore, as Moody and Paxton (2009) point out, it is difficult to divorce the structure of social networks from social capital and we are better served by carefully predicting the outcomes of each.

\section{Policy implications}

The analysis revealed that the dynamics of production and inclusion differed quite substantially and therefore require different policy approaches. The mango case suggested a combined policy approach that bridges the divide between exporters and non-exporters that will reduce exclusions created by exclusive access to exporters. However, policy measures that support different export models (large-scale commodity production by APEM and smaller scale production based on organic and fair trade) can increase cluster diversity and strengthen options for inclusion. For the palm oil cluster the discussion of inclusion will be influenced by the dominant role of the large refinery organisations that also acts as buyer of the produce of small scale farmers. Increasing the diversity of the cluster by broadening the provision of services to small producers and lessening the dependence on one central anchor organisation will reduce small producer vulnerability and is likely to enrich provision of knowledge.

\section{Acknowledgments}

The authors would like to thanks the British Academy for their support (Grant SG50694) and APEM, PROMANGO and CENIPALMA for facilitating interviews. Also the reviewers for their insightful comments.

\section{Appendix A. Supplementary material}

Supplementary data associated with this article can be found, in the online version, at http://dx.doi.org/10.1016/j.foodpol.2018.04.005.

\section{References}

Agrawal, A., Ostrom, E., 2001. Collective action, property rights, and decentralization in resource use in India and Nepal. Polit. Soc. 29 (4), 485-514. http://dx.doi.org/10. $1177 / 0032329201029004002$.

Altenburg, T., Meyer-Stamer, J., 1999. How to promote clusters: policy experiences from Latin America. World Dev. 27 (9), 1693-1713. http://dx.doi.org/10.1016/S0305750X(99)00081-9.

Bandiera, O., Rasul, I., 2006. Social network and technology adoption in northern Mozambique. Econ. J. 116, 869-902.

Bardhan, P., Udry, C., 1999. Development Microeconomics. OUP, New York.

Barabási, A.-L., 2003. Linked: how everything is connected to everything else and what it means for business, science, and everyday life. Book. http://dx.doi.org/10.1146/ annurev.soc.30.020404.104342.

Bebbington, A., 1997. Social capital and rural intensification: local organisations and islands of sustainability in rural Andes. The geographical journal 163 (2), 187-197. http://dx.doi.org/10.2307/3060182.

Bebbington, A., 1998. Sustaining the Andes? Social capital and policies for rural regeneration in Bolivia, Mountain Research and Development 18 (2), 173-181. http:// dx.doi.org/10.2307/3673972.

Bebbington, A., 2012. Social conflict, economic development and extractive industry: evidence from South America. In: Social Conflict, Economic Development and 
Extractive Industry: Evidence from Latin Americaevelopment and Extractive Industry: Evidence from South America, pp. 3-26. http://dx.doi.org/10.1080/ 03066150.2013 .801638 .

Bebbington, A., Abramovay, R., Chiriboga, M., 2008. Social movements and the dynamics of rural territorial development in Latin America. World Dev. 36 (12), 2874-2887. http://dx.doi.org/10.1016/j.worlddev.2007.11.017.

Bebbington, A., Guggenheim, S., Olson, E., Woolcock, M., 2004. Exploring social capital debates at the World Bank. J. Dev. Stud. 40 (5), 33-64. http://dx.doi.org/10.1080/ 0022038042000218134 .

Bell, M., Giuliani, E., 2007. Catching up in the global wine industry: innovation systems, cluster knowledge networks and firm-level capabilities in Italy and Chile. Int. J. Technol. Global. 3 (2-3), 197-223.

Bernard, T., Spielman, D.J., 2009. Reaching the rural poor through rural producer organizations? A study of agricultural marketing cooperatives in Ethiopia. Food Policy 34 (1), 60-69. http://dx.doi.org/10.1016/j.foodpol.2008.08.001.

Burt, R.S., 1992. Structural Holes: The Social Structure of Competition. Harvard University Press, Cambridge, Massachussetts, pp. 38-40. http://dx.doi.org/10.1177/ 0265407512465997.

Cáceres, D.M., 2015. Accumulation by dispossession and socio-environmental conflicts caused by the expansion of agribusiness in Argentina. J. Agrarian Change 15 (1) 116-147. http://dx.doi.org/10.1111/joac.12057.

Cagnin, C., Amanatidou, E., Keenan, M., 2012. Orienting european innovation systems towards grand challenges and the roles that FTA can play. Sci. Public Policy 39 (2), 140-152. http://dx.doi.org/10.1093/scipol/scs014.

Carbajal, M.M., Hernandez, S.P., 2008. Avocado production and the sectoral innovation, system. Paper presented at VI Globelics conference, Mexico City.

Carpenter, M.A., Li, M., Jiang, H., 2012. Social network research in organizational contexts: a systematic review of methodological issues and choices. J. Manage. 38 (4), 1328-1361. http://dx.doi.org/10.1177/0149206312440119.

Carter, N., 1996. Halting degradation of natural resources: Is there a role for rural communities? - Baland, JM, Platteau, JP. Int. Affairs Royal Inst. Int. Affairs 1944 (72), 821. http://dx.doi.org/10.2307/2624181.

Clarke, I., Ramirez, M., 2014. Intermediaries and capability building in "emerging" clusters. Environ. Plann. C: Govern. Policy 32 (4). http://dx.doi.org/10.1068/ c1262r.

Coleman, J., 2000. Social capital in the creation of human capital. Knowl. Soc. Capital 17-41. http://dx.doi.org/10.1016/B978-0-7506-7222-1.50005-2.

Cordoba, A.H., 2011. Promocion y Desarrollo de la Asistencia Técnica, Power point, presentation, Bucaramanga, Colombia.

Darr, D., Pretzsch, J., 2008. Mechanisms of innovation diffusion under information abundance and information scarcity - on the contribution of social networks in group vs. individual extension approaches in semi-arid Kenya. J. Agric. Educ. Extens. 14, 231-248. http://dx.doi.org/10.1080/13892240802207676. (October 2013).

de Nooy, W., 2011. Networks of action and events over time. A multilevel discrete-time event history model for longitudinal network data. Soc. Networks 33 (1), 31-40. http://dx.doi.org/10.1016/j.socnet.2010.09.003.

Devaux, A., Horton, D., Velasco, C., Thiele, G., López, G., Bernet, T., et al., 2009. Collective action for market chain innovation in the Andes. Food Policy 34 (1), 31-38. http://dx.doi.org/10.1016/j.foodpol.2008.10.007.

Dolan, C., Humphrey, J., 2000. Governance and trade in fresh vegetables: the impact of UK supermarkets on the African horticulture industry. J. Dev. Stud. 37 (2), 147-176. http://dx.doi.org/10.1080/713600072.

Dolan, C., Humphrey, J., 2004. Changing governance patterns in the trade in fresh vegetables between Africa and the United Kingdom. Environ. Plann. A 36 (3), 491-509. http://dx.doi.org/10.1068/a35281.

Essex, J., 2008. Biotechnology, sound science, and the foreign agricultural service: a case study in neoliberal rollout. Environ. Plann. C: Govern. Policy 26 (1), 191-209. http:// dx.doi.org/10.1068/c61m.

Fafchamps, M., 2006. Development and social capital. J. Dev. Stud. 42 (7), 1180-1198. http://dx.doi.org/10.1080/00220380600884126.

Fernandez-stark, K., Bamber, P., Gereffi, G., 2012. Inclusion of small- and medium-sized producers in value chains. Center Global., Govern. Competit. 1-38.

Giuliani, E., Bell, M., 2005. The micro-determinants of meso-level learning and innovation: evidence from a Chilean wine cluster. Res. Policy 34 (1), 47-68. http://dx.doi. org $/ 10.1016 / \mathrm{j}$.respol.2004.10.008.

Goldberger, J.R., 2008. Non-governmental organizations, strategic bridge building, and the "scientization" of organic agriculture in Kenya. Agric. Hum. Values 25, 271-289. http://dx.doi.org/10.1007/s10460-007-9098-5.

Hardin, G., 1968. The tragedy of the commons. Science (New York, N.Y.) 162 (3859), 1243-1248. http://dx.doi.org/10.1126/science.162.3859.1243.

Hartwich, F., Halgin, D., Monge, M., 2008. How Change Agents and Social Capital Influence the Adoption of Innovations among Small Farmers. Evidence from Social Networks in Rural Bolivia. IFPRI Discussion Paper, (April), 76 ST-How Change Agents and Social Capital Infl. http://doi.org/10.5367/000000008784648889ET-00761.

Hellin, J., Lundy, M., Meijer, M., 2009. Farmer organization, collective action and market access in Meso-America. Food Policy 34 (1), 16-22. http://dx.doi.org/10.1016/j. foodpol.2008.10.003.

Heller, P., Isaac, T.M., 2003. Democracy and development: decentralized planning in Kerala. In: Fung, A., Wright, E.O. (Eds.), Deepening Democracy, Verso, London, pp. 77-110.

Hirschman, A.O., 1970. Exit, Voice and Loyalty: Responses to Decline in Firms, Organisations and States. Mass. Harvard University Press, Cambridge.

Hoff, K., 2001. Beyond Rosenstein-Rodan : the modern theory of coordination problems in development. In: Annual World Bank Conference on Development Economics, 2000, 2000(2000), pp. 145-188.

Humphrey, J., 2006. Global Value Chains in the Agri-food Sector, United Nations
Development Organisation, Working paper, Vienna.

Isham, J., 2002. The effect of social capital on fertiliser adoption: evidence from rural tanzania. J. Afr. Econ. 11 (1), 39-60. http://dx.doi.org/10.1093/jae/11.1.39.

Jan van Roekel, N., Kopicki, R., Broekmans, C.J.E., Boselie, D.M.C.N., 2002. Building Agri Supply Chains: Issues and Guidelines. World Bank Paper Cross-Border Agri Supply Chain Management, c, 18. Retrieved from internal-pdf://51.11.189.61/ AgriSupplyChains.pdf (+31735286659 acc@kc-acc. or).

Kherallah, M., Delgado, C., Gabre-Madhin, E., Minot, N., Johnson, M., 2002. Reforming agricultural markets in Africa (review). In: Africa Today, http://dx.doi.org/10.1353/ at.2004.0051.

Kumar, A., Francis, P., Apfalter, S., 2010. Main Report. World Bank, Washington DC. $<$ http://documents.worldbank.org/curated/en/977931468154789057/Mainreport $>$.

Lahai, B.A.N., Goldey, P., Jones, G.E., 1999. The gender of the extension agent and farmers' access to and participation in agricultural extension in Nigeria. J. Agric. Educ. Extens. 6 (4), 223-233. http://dx.doi.org/10.1080/13892240085300051.

Liverpool-Tasie, L.S.O., Winter-Nelson, A., 2012. Social learning and farm technology in Ethiopia: impacts by technology, network type, and poverty status. J. Dev. Stud. 48 (10), 1505-1521. http://dx.doi.org/10.1080/00220388.2012.693167.

Mansuri, G., Rao, V., 2013. Localizing Development: Does Participation Work? The World Bank, Washington, DC.

Markelova, H., Meinzen-Dick, R., Hellin, J., Dohrn, S., 2009. Collective action for smallholder market access. Food Policy 34 (1), 1-7. http://dx.doi.org/10.1016/j. foodpol.2008.10.001.

McDermott, G.A., Corredoira, R.A., Kruse, G., 2009. Public-private institutions as catalysts of upgrading in emerging market societies. Acad. Manage. J. 52 (6), 1270-1296. http://dx.doi.org/10.5465/amj.2009.47084929.

McPherson, M., Smith-Lovin, L., Cook, J.M., 2001. Birds of a feather: homophily in social networks. Annu. Rev. Sociol. 27 (1), 415-444. http://dx.doi.org/10.1146/annurev. soc.27.1.415.

Moody, J., Paxton, P., 2009. Building bridges: linking social capital and social networks to improve theory and research. Am. Behav. Sci. 52 (11), 1491-1506. http://dx.doi.org/ $10.1177 / 0002764209331523$

Morris, J., 1991. Extension Alternatives in Tropical Africa. ODI, London.

Moser, C.O.N., 1998. The asset vulnerability framework: reassessing urban poverty reduction strategies. World Dev. 26 (1), 1-19. http://dx.doi.org/10.1016/S0305-750X (97)10015-8.

Narayan, D., 1999. Bonds and bridges: social capital and poverty. World 2167, 58. http:// dx.doi.org/10.1017/СВO9781107415324.004.

Olson, M., 1965. The logic of collective action Cambridge. Public Goods Theory Groups. http://dx.doi.org/10.1007/978-3-319-20451-2_32.

Ostrom, E., 2015. Governing the Commons: The Evolution of Institutions for Collective Action. http://doi.org/10.1017/CBO9781316423936.

Pelling, M., High, C., 2005. Understanding adaptation: What can social capital offer assessments of adaptive capacity? Global Environ. Change. http://dx.doi.org/10.1016/ j.gloenvcha.2005.02.001.

Rao, V., Ibáñez, A.M., 2005. The social impact of social funds in Jamaica: a "participatory econometric" analysis of targeting, collective action, and participation in communitydriven development. J. Dev. Stud. 41 (5), 788-838. http://dx.doi.org/10.1080/ 00220380500145297.

Roeling, N., 2007. Communication for Development in Research, Extension and Education.

Rogers, E.M., 2010. Diffusion of Innovations. Simon and Schuster.

Roundtable on Sustainable Palm Oil, 2013. RSPO Principles and Criteria for Sustainable Palm Oil Production. RSPO.

Schmitz, H., 1995. Collective efficiency: growth path for small-scale industry. J. Dev. Stud. 31 (4), 529-566. http://dx.doi.org/10.1080/00220389508422377.

Soumonni, O., 2010. Distributed generation: an alternative paradigm for electrification in West Africa. In: Globelics, Conference in Kuala Lumpur.

Sugden, R., Sen, A., 1986. Commodities and capabilities. Econ. J. 96 (383), 820. http:// dx.doi.org/10.2307/2232999.

Thompson, G., 2003. Between hierarchies and markets: the logic and limits of network forms of organization. Am. J. Sociol. 110. http://dx.doi.org/10.1093/acprof.

Thompson, J., Scoones, I., 1994. Challenging the populist perspective: rural people's knowledge, agricultural research, and extension practice. Agric. Hum. Values 11 (2-3), 58-76. http://dx.doi.org/10.1007/BF01530446.

Thorp, R., Stewart, F., Heyer, A., 2005. When and how far is group formation a route out of chronic poverty? World Dev. 33 (6), 907-920. http://dx.doi.org/10.1016/j. worlddev.2004.09.016.

UNDP, 2010. Crecimiento de mercados inclusivos: Estrategias empresariales para la superación de la probreza y la exclusión en Colombia. Report for "Growing Inclusive Markets Project, Bogota.

Vidal, M.R., 2011. Le economía del paramilitares, redes de corrupción, negocios y política. Debate, Bogota.

Visser, E.J., 1999. A comparison of clustered and dispersed firms in the small-scale clothing industry of Lima. World Dev. 27 (9), 1553-1570. http://dx.doi.org/10 1016/S0305-750X(99)00077-7.

Vorley, B., Pozo-Vergnes, V., Barnett, A., 2008. Small Producer Agency in the Globalised Market: Making Choices in a Changing World. International Institute for Environment, and Development, London.

\section{Further reading}

Gomez, C.A.C., 2012. Panorama de la agroindustria de la palma de aceite nacional y de la Zona, Central, power point presentation, Sabana de Torres, Colombia. 